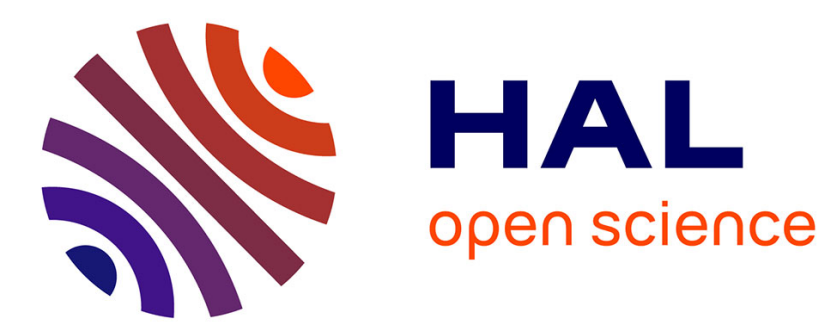

\title{
Historical Note: On the simulation of dispersive wave propagation by elasticity models
}

\author{
Alfred Seeger
}

\section{To cite this version:}

Alfred Seeger. Historical Note: On the simulation of dispersive wave propagation by elasticity models. Philosophical Magazine, 2010, 90 (09), pp.1101-1104. 10.1080/14786430903292357 . hal-00581018

\section{HAL Id: hal-00581018 https://hal.science/hal-00581018}

Submitted on 30 Mar 2011

HAL is a multi-disciplinary open access archive for the deposit and dissemination of scientific research documents, whether they are published or not. The documents may come from teaching and research institutions in France or abroad, or from public or private research centers.
L'archive ouverte pluridisciplinaire HAL, est destinée au dépôt et à la diffusion de documents scientifiques de niveau recherche, publiés ou non, émanant des établissements d'enseignement et de recherche français ou étrangers, des laboratoires publics ou privés. 


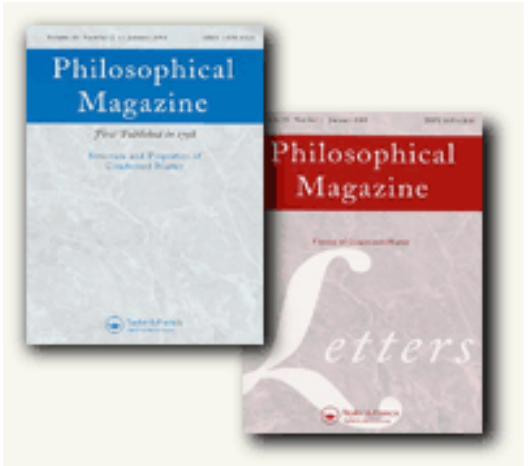

\section{Historical Note: On the simulation of dispersive wave propagation by elasticity models}

\begin{tabular}{|r|l|}
\hline Journal: & Philosophical Magazine \& Philosophical Magazine Letters \\
\hline Manuscript ID: & TPHM-09-Aug-0369 \\
\hline Journal Selection: & Philosophical Magazine \\
\hline $\begin{array}{r}\text { Date Submitted by the } \\
\text { Author: }\end{array}$ & 27-Aug-2009 \\
\hline Complete List of Authors: & Seeger, Alfred; Max-Planck Institut fuer Metallforschung \\
\hline Keywords: & elastic waves, simulation \\
\hline Keywords (user supplied): & $\begin{array}{l}\text { Dispersive wave propagation, Born-von Kármán model, } \\
\text { Schrödinger's solution }\end{array}$ \\
\hline
\end{tabular}

\section{scholarONE" \\ Manuscript Central}




\title{
Historical Note: On the simulation of dispersive wave propagation by elasticity models
}

\author{
Alfred Seeger* \\ Universität Stuttgart, Institut für theoretische und angewandte Physik, Stuttgart, Germany \\ Max-Planck-Institut für Metallforschung, Heisenbergstr 3, Stuttgart, Germany
}

(Received ..... March 2009)

Attention is called to E. Schrödinger's elegant analytical solution [Annalen Physik 44 (1914) 916] of the initial-value problem for the Born-von Kármán model of an infinite one-dimensional chain of uniformly spaced particles of mass $M$ with nearest-neighbour coupling by harmonic springs. This model has recently served as the starting point for a computer study of the transition to partial differential equations describing dispersive wave propagation in inhomogeneous media $[\mathrm{H}$. Askes et al., Philos. Mag. 88 (2008) 3415]. Schrödinger's solution allows the main features of the limit process involved in this transition to be studied in a straightforward way.

Keywords: Dispersive wave propagation, Born-von Kármán model, Schrödinger's solution, transition to generalized continua

The recent paper entitled „Four simplified gradient elasticity models for the simulation of dispersive wave propagation" [1], aiming at the development of so-called gradient elasticity theories to simulate propagation of mechanical waves in heterogeneous media, employed as starting point Born and von Kármán's [2] well-known model of a one-dimensional chain of particles of mass $M$ in which adjacent particles interact through harmonic springs of stiffness $K$. Within the framework of Newtonian mechanics, in this model the particle displacements $y_{n}(t)(n=0, \pm 1, \pm 2, \ldots ; t=$ time $)$ are governed by the difference-differential equation

$$
M \ddot{y}_{n}=K\left[y_{n-1}(t)-2 y_{n}(t)+y_{n+1}(t)\right]
$$

The approach of Askes et al. [1] replaces the discrete displacements $y_{n}(t)$ by their continuous counterparts $y(x \pm l, t)(l=0, \pm 1, \pm 2, \ldots ; x=$ spatial coordinate along the chain $)$ and investigates the partial differential equations that result from breaking off the Taylor expansion of $y(x \pm l, t)$ at various orders of $l^{2}$. The simplest outcome is the one-dimensional wave equation

$$
\partial^{2} y(x, t) / \partial t^{2}-c^{2} \partial^{2} y(x, t) / \partial x^{2}=\mathrm{O}\left(l^{2}\right)
$$

According to d'Alembert, the general solution of eqn (2) may be expressed in terms of two arbitrary functions $\mathrm{f}_{1}(z), \mathrm{f}_{2}(z)$ as

$$
y(x, t)=\mathrm{f}_{1}(x-c t)+\mathrm{f}_{2}(x+c t)
$$

hence as a superposition of dispersion-free waves with speed $c$. By contrast, the solutions of eqn (1) are waves with dispersion according to

$$
\omega^{2}=(4 K / M) \sin ^{2}(k a / 2)
$$

where $\omega$ denotes the circular frequency, $k$ the wave number of the waves and $a$ the nearestneighbour distance in the chain. 
The influence of the different dispersion laws of eqns (1) and (2) on the behaviour of the solutions may be profound, as will be discussed below. In their attempt to modify eqn (2) by adding on its right-hand side fourth-order derivatives of the displacement $u(x, t)$ in such a way that the resulting partial differential equation retains characteristic features of the differencedifferential equation (1), Askes et al. [1] apparently overlooked that already in 1914 Erwin Schrödinger (1887-1961) addressed the relationship between the discrete description (1) of the Born-von Kármán model and the continuum approximation (2) in considerable depth [3]. He solved the initial-value problem of eqn (1) in an explicit form that allows most of the salient questions to be answered rather directly.

Schrödinger's scientific biographer, Walter Moore, describes Schrödinger's paper as follows [4]: "This paper is undoubtedly the most interesting of all those written by Schrödinger before he was called into military service in 1914. It carries forward one of the basic problems of 'grandfather Boltzmann' by its penetrating analysis of the specification of initial values in a system based on an atomic model, and it forms a bridge to his later revolutionary applications of differential equations of wave motion in his wave mechanics. In this paper also, for the first time, we hear the authentic Schrödinger style, with its urban confidence and its ability to relate the question in hand to deeper philosophic concerns of mathematical physics." A summary and critical discussion of Schrödinger's solution of the initial-value problem may be found in Günther Leibfried's contribution to the Encyclopedia of Physics [5].

In his paper [3], Schrödinger recognized that the introduction of new variables

$$
u_{2 n}:=M^{1 / 2} \square_{n}, \quad u_{2 n+1}:=K^{1 / 2}\left(y_{n}-y_{n+1}\right) \quad(n=\ldots,-1,0,+1, \ldots)
$$

allows the original system (1) to be rewritten as

$$
\mathrm{d} u_{n} / \mathrm{d} t=-\omega\left(u_{n+1}-u_{n-1}\right) / 2, \omega=2(K / M)^{1 / 2}(n=\ldots,-1,0,+1, \ldots) .
$$

Eqn $\left(6_{1}\right)$ is one of the two basic functional equations of cylinder functions of order $n$ and argument $\omega t[6]$. Hence a solution of eqns (6) is

$$
u_{n}(t)=\sum_{m=-\infty}^{m=\infty} u_{m}{ }^{0} \mathrm{~J}_{n-m}(\omega t) \quad(n=\ldots,-1,0,+1, \ldots)
$$

where $\mathbf{J}_{n-m}(\omega t)$ denotes Bessel functions (cylinder functions of the first kind) of order $n-m$. The physical meaning of the constants of integration, $u_{m}{ }^{0}$, will become clear presently.

Suppose that at $t=0$ all particles in the chain are at rest (implying $\left.\square_{n}(0) \equiv 0\right)$ and that they are located at their regular positions in the chain with the sole exception of the particle numbered zero, which has been displaced by $y_{0}{ }^{0}$. With $\mathrm{J}_{n}(0)=\delta_{10}$ [6], valid for integer $n$, we find from eqns $\left(5_{2}\right)$ and $(7)$ that all $u_{m}{ }^{0}$ vanish with the two exceptions of

$$
u_{ \pm 1}^{0}= \pm K^{1 / 2} y_{0}^{0}
$$

hence (cf. [6])

$$
u_{n}(t)=K^{1 / 2} y_{0}^{0}\left[\mathrm{~J}_{n-1}(\omega t)-\mathbf{J}_{n+1}(\omega t)\right]=2 K^{1 / 2} y_{0}^{0} \mathrm{~d} \mathbf{J}_{n}(\omega t) / \mathrm{d} \omega t .
$$




$$
y_{0}(t)=y_{0}^{0} \mathbf{J}_{0}(\omega t)
$$

requires a special derivation but is nevertheless covered by eqn (10).

As discussed in the literature [3-5], there are striking differences between the exact solution eqn (11) and the predictions following to order $l^{0}$ from the one-dimensional wave equation (2). Whereas according to eqn (3) any localized displacement (say, at $x=0, t=0$ ) migrates with the limit speed $c$, eqn (10) predicts that even at arbitrarily small $t>0$ very distant particles begin to move. However, this movement starts more and more slowly the larger the distance from $m=0$, as may be seen from the leading term of the Taylor expansion of eqn (10),

$$
\mathrm{J}_{2 n}(\omega t)=(K / M)^{n} t^{2 n} /(2 n) !+\mathrm{O}\left(t^{2(n+1)}\right) .
$$

If $\omega t \rightarrow \infty$, the Bessel functions may be replaced by the leading term of their Hankel-type asymptotic expansions,

$$
\mathrm{J}_{2 n}(\omega t) \sim(2 / \pi \omega t)^{-1 / 2} \cos [\omega t-(n+1 / 4) \pi] .
$$

We see that at large times the chain vibrates with the circular frequency eqn $\left(6_{2}\right)$ and the wavelength $2 a$. (Note that these are the highest frequency and the shortest wavelength that are physically meaningful.) The amplitude of this vibration decreases as $t^{-1 / 2}$. This is a consequence of the fact that in an infinite chain the energy originally supplied at $n=0, t=0$ continues to spread indefinitely (approximately with the speed $[K / M]^{1 / 2} a$ ). Had we Fourieranalysed the original excitation, the distribution of the energy on the different eigenmodes would be time-independent, since owing to the linearity of the system there is no energy transfer between the modes.

Further asymptotic expansions of the Bessel functions are available in the literature [6]. An example is the Nicholson-type expansion with the leading term

$$
\mathbf{J}_{2 n}(\omega t) \sim(\omega t / 2)^{-1 / 3} \operatorname{Ai}\left[(\omega t / 2)^{-1 / 3}(2 n-\omega t)\right],
$$

where $\mathrm{Ai}[z]$ denotes one of the Airy functions [6]. Eqn (14) is valid if $\omega t / 2 n$ is of the order of magnitude of unity and $|2 n-\omega t|$ is large.

Schrödinger's work [3] was strongly influenced by two questions that were hotly debated at the beginning of the $20^{\text {th }}$ century:

(i) Under which conditions do continuum models of matter give demonstrably wrong results because they disregard the atomistic structure of matter?

(ii) What limits the thermal conductivity in crystalline materials?

The first question is relevant for the work of Askes et al. [1]. Schrödinger's answer was that in order to get the right answer one had to consider averages of the variables over regions that 3 
contained many atoms. In general, it is not sufficient to perform an expansion in powers of $l$, since the resulting limits may be physically irrelevant.

The second question was raised by Schrödinger - though only in passing - because he considered the $t^{-1 / 2}$ decay law mentioned above to be closer to the heat conduction by lattice vibrations (the name 'phonon' was not yet in use) than to the wave propagation in one dimension. His opinion that harmonic forces as in the Born-Huang model eqn (1) could give a finite thermal conductivity even in the absence of imperfections and/or surfaces was later proved wrong, however [7].

\section{References}

[1] H. Askes, A. V. Metrikine, A. V. Pichugin and T. Bennett, Philos. Mag. 88 (2000) p. 3415

[2] M. Born and Th. von Kármán, Phys. Zeitschr. 18 (1912) p.297

[3] E. Schrödinger, Ann. Physik (Lpzg) 44 (1914) p.916

[4] W. J. Moore, Schrödinger - life and thought, Cambridge Univ. Press, Cambridge 1989, p.78

[5] G. Leibfried, in Encyclopedia of Physics, Vol. VII/1, S. Flügge ed., Springer, Berlin etc. 1955, p.190

[6] W. Magnus, F. Oberhettinger and R. P. Soni, Formulas and theorems for the special functions of mathematical physics, Springer, Berlin etc. 1966

[7] R. E. Peierls, Quantum theory of solids, Clarendon Press, Oxford 1955, §2.4 
